\title{
Role of Mothers’ Nutritional Knowledge, Nutritional Factors on the School Performance
}

\author{
JasminAra Farhana1, Farhana Akther², MesbahUddin Talukder², Md. Ariful Islam², \\ Md. Torikul Islam ${ }^{1}$, Md. AminulHaque Bhuyan ${ }^{1}$ \\ ${ }^{1}$ Institute of Nutrition and Food Science, University of Dhaka, Dhaka, Bangladesh \\ ${ }^{2}$ Department of Food Technology and Nutritional Science, MawlanaBhashani Science and Technology University, \\ Tangail, Bangladesh
}

\begin{abstract}
Article Info
Article history:

Received Jan 01, 2015

Revised Jan 30, 2015

Accepted Feb 26, 2015

\section{Keyword:}

BMI

Children

Knowledge

Nutritional Factors

School Performance

ABSTRACT

A cross sectional study was carried out to investigate the effects of mothers' nutritional knowledge, health and nutritional factors and socio-economic parameters on school performance among class five students of University Laboratory School, Dhaka. All of the eighty students were selected for this study. This study found there is a strong relationship between mother's knowledge score and school performance. It was found that mothers' knowledge score was responsible for 91.1 percent change in school performance. The mean BMI of the mothers was 20.44. We found that the school performance measured by class roll number of the students is significantly related with mothers BMI. There was an imperfect negative association between socio-economic parameters and school performance. But the relationship between the school performances with socio-economic parameters was strongly significant. This study also observed the relationship between Individual Dietary Diversity Score (IDDS) of respondent and marks achieved in class 4 final exam. It is alarming that consumption percentage were low for eggs (30) and milk and milk products (37.5), but majority of the students who consumed milk and milk products (63.3\%) and eggs (66.7\%) got the highest marks.
\end{abstract}

Copyright (C) 2015 Institute of Advanced Engineering and Science. All rights reserved.

\section{Corresponding Author:}

MesbahUddin Talukder, Department of Food Technology and Nutritional Science, MawlanaBhashani Science and Technology University, Tangail, Bangladesh.

Email: mesbah_du06@yahoo.com

\section{INTRODUCTION}

Children are the wealth of any nation as they constitute one of the important segments of the population. School age is the active growing phase of childhood. Primary school age is a dynamic period of physical growth as well as of mental development of the child [1]. Children in the age group of 5-14 years are often considered as school-age. Since 1972, the United Nations Educational Scientific and Cultural Organization (UNESCO) consider 6-11 years as primary school age and 12-17 years as secondary school age for statistical purposes. The health well being of children is a fundamental issue in education. Indeed, active promotion of health is now seen as a priority for school. In countries around the world, the issue is being addressed through school health services, health education and school meals programmers [2].

The children themselves, of course, with their unique abilities, temperaments and propensities play a central role in forming and reforming their behavior, aspirations and achievements [3]. Parents, the broader family, peer groups, neighborhood influences, schools and other bodies (e.g. churches, clubs) are all implicated in shaping children's progress towards their self fulfillment and citizenship. Nutritionally educated mothers can bring up their children in a healthier way [4]. There is a positive association between 
the mothers' nutrition knowledge and the children's weight-for-age [5]. Mother's knowledge on nutrition has a significant positive influence on children's diet quality and children's dietary intakes. Recent research shows that children's health can affect their schooling outcomes. Height for age, a cumulative indicator of children's health status, increases school enrollment [6]. A mother with just a few years of schooling is more likely to provide her children with the care and stimulation that will dramatically improve their early, formative years than the mother who has never received any formal education at all. Illustratively, one study found that a single year of mother's education was associated with a 9 percent decrease in child mortality [7].

Research indicates that health problems due to miserable nutritional status in primary school-age children are among the most common causes of low school enrolment, high absenteeism, early dropout and unsatisfactory classroom performance. It is therefore important that mothers are educated on proper nutrition so that they could cater to the growing needs and for a better nutritional status of their children that will help their children on better school achievement [8]. The socioeconomic status of a child is usually determined by parental educational level, parental occupational status and income level. It is understood that low socioeconomic status negatively and depressingly affects students' academic achievement [9].

School age is considered as a dynamic period of growth and development because children undergo physical, mental, emotional and social changes. In other words the foundations of good health and sound mind are laid during the school age period. Hence the present study was formulated with the objective, to assess and find the effects of mothers' nutritional knowledge, health and nutritional factors and socioeconomic parameters on the school performance of selected primary school going children and to provide baseline data for future research.

\section{RESEARCH METHOD}

Type of study

A cross sectional sample survey was carried out among 5 graders students of University Laboratory School \& College (ULAB) in Dhaka city.

Basis for selection of study place:

$>$ Well communicated.

$>$ Assurance from the school authority for full co-operation.

Study population and sample size:

The study population was the 5 graders students of University Laboratory School \& College (ULAB). There were 80 students in grade 5 . As because there were only 80 students, that's why all of them are included in my study. So sample size $(\mathrm{N})$ is also 80.

\section{Research Instruments:}

Development of the questionnaire:

A questionnaire was developed containing both close and open ended questions to obtain relevant information on internet exposure, socio-economic and demographic condition.

\section{Data Collection:}

Questionnaire was asked passively and cautiously not to influence the respondents. Measuring instruments were Bathroom scale/Salter scale: Weight measurement \& Modified tape: Height measurement.

\section{Collection of socio-economic, demographic and Food behavior information:}

The part of the questionnaire that was designed to obtain socio-economic information was collected by interviewing the respondents. All of the respondents were interviewed about health, educational information, occupation, family size, income, living condition etc. All of the information's were recorded in the respective places of the questionnaire.

\section{Pilot survey}

A pilot survey was conducted to test the efficiency of the questionnaire, to look for any problem in the methodology and to improve the skill in collecting the data.

\section{Anthropometric Measurements:}

Weight and height were measured according to standardized procedure using appropriate device. 


\section{Data Verification:}

Questionnaires were checked each day after interviewing and again these were carefully checked after completion of all data collection and coded before entering into the computer. The data was edited if there was any discrepancy (doubt entry, wrong entry etc).

\section{Statistical Analysis:}

All of the statistical analysis and all other data processing were done by using SPSS 16.0 windows program. For tabular, charts and graphical representation Microsoft Word and Microsoft Excel was used.

\section{RESULTS AND ANALYSIS}

Table 1 shows the percent distribution of the health and nutritional factors that affects the school performance of the student. The study found that half of the mothers belong to normal weight. Among the mothers, 52.5 percent belongs to normal weight whereas 36.2 percent were under weight and 11.2 percent were overweight. The respondent mothers had not uniform perception about their own health. About 27.5 percent mothers thought that their health is good where as 23.8 mothers thought they have excellent health condition. It was found that most of the mothers did not have chronic diseases. Only 6.2 percent mothers have diabetes, 5 percent have asthma, 8.8 percent have heart disease and 5 percent have lung disease. But the mothers are conscious about their child's education. Half of the mothers take care of child's education where as only 10 percent of the fathers are concerned of their child's education.

Table 1. Percent distribution of health and nutritional factors influencing school performance $(\mathrm{n}=80)$

\begin{tabular}{clcc}
\hline \multicolumn{1}{c}{ Variable } & \multicolumn{1}{c}{ Category } & Frequency & Percent (\%) \\
\hline Category of mothers BMI & Under weight & 29 & 36.2 \\
& Normal weight & 42 & 52.5 \\
& Over weight & 9 & 11.2 \\
Mothers own perception about health & Excellent & 19 & 23.8 \\
& Very good & 19 & 23.8 \\
& Good & 22 & 27.5 \\
& Fair & 12 & 15.0 \\
& Poor & 8 & 10.0 \\
Mothers chronic disorder & Diabetes & 5 & 6.2 \\
& Asthma & 4 & 5.0 \\
& Heart disease & 7 & 8.8 \\
& Lung disease & 4 & 5.0 \\
Takes care about education & No chronic disease & 60 & 75 \\
& Father & 10 & 12.5 \\
& Mother & 40 & 50.0 \\
& Both & 11 & 13.8 \\
& None & 5 & 6.2 \\
& Teacher & 14 & 17.5 \\
\hline
\end{tabular}

Table 2. Descriptive statistics of health and nutritional factors of school performance $(n=80)$

\begin{tabular}{lcccc}
\hline \multicolumn{1}{c}{ Variable } & (Mean \pm S.E.) & S.D. & Minimum & Maximum \\
\hline Mothers BMI & $20.44 \pm 0.28$ & 2.53 & 16.23 & 26 \\
Marks obtained in class 4 final exam & $599.01 \pm 12.91$ & 115.55 & 432 & 810 \\
Percentage of marks obtained in class 4 & $70.47 \pm 1.52$ & 13.59 & 51 & 95 \\
final exam & & & & \\
\hline
\end{tabular}

Table 2 represents the mean, standard deviation, minimum and maximum value for health and nutritional factors that affects school performance. The mean of BMI of the mothers was 20.44. It was found that a highest 95 percent marks was achieved which is equivalent to 810 marks whereas lowest 432 marks was achieved in class 4 final exam. The mean for percentage of marks obtained in class 4 final exam and total marks obtained in class 4 final exam were 70.47 percent and 599.01 respectively. 


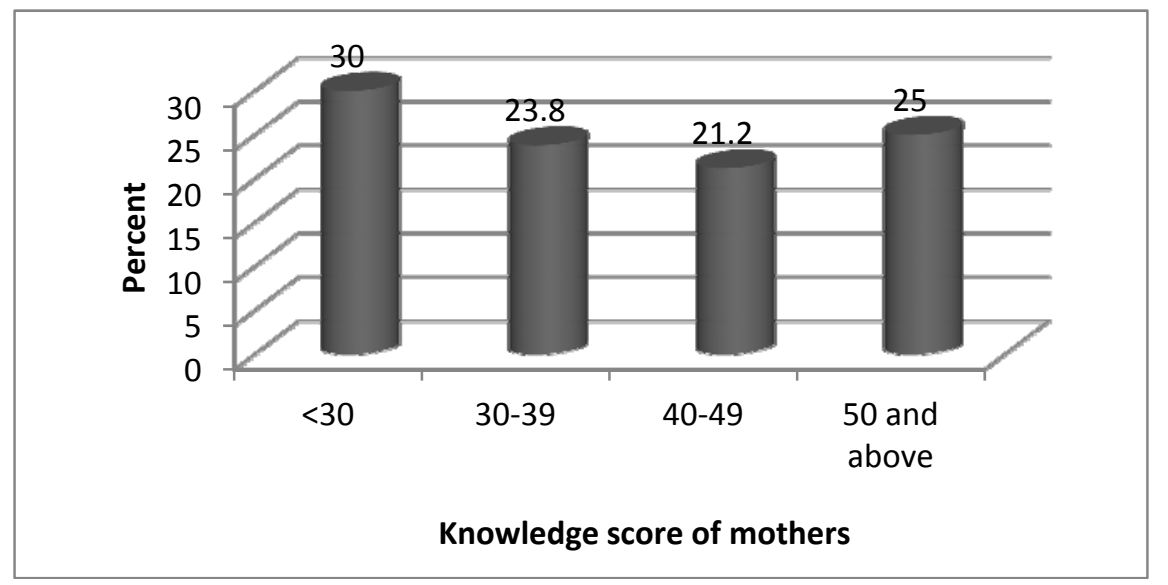

Figure 1. Percent distribution of Knowledge score of mothers

Figure 1 depicts the percent distribution of knowledge score of mothers. This study found that only 25 percent mothers obtained 50 and above marks, 21.2 percent obtained 40-49, 23.8 percent obtained 30-39 and 30 percent obtained less than 30 marks.

Table 3. Correlation coefficient showing the effects of nutritional factors and socio-economic parameters on school performance

\begin{tabular}{cccc}
\hline \multicolumn{4}{c}{ Correlation between nutritional factors and school performance } \\
\hline Dependent variable & Independent variable & Correlation coefficient & P-value \\
School Performance & Total knowledge score & -0.954 & 0.000 \\
& Mothers BMI & -0.886 & 0.000 \\
\hline \multicolumn{2}{c}{ Correlation between socio-economic parameters and school performance } \\
\hline School Performance & Total income of the family & -0.940 & 0.000 \\
& Monthly tuition cost & -0.958 & 0.000 \\
& No of earning person in family & -0.891 & 0.000 \\
\hline
\end{tabular}

Table3 illustrates the association between nutritional factors and school performance measured by class roll number. It represents that there is an imperfective negative correlation between school performance and total knowledge score. This table also shows the correlation coefficient between BMI and school performance is -0.886 indicating the negative association. The relationship between school performance and total knowledge score is strongly significant as the p-value is zero. This indicates that their performances are not same due to the different values of the mentioned total knowledge score related variables. This table also shows that the school performance measured by class roll number of the students is significantly related with mothers BMI, marks obtained in class 4 final exam, because the Chi-square test shows the p-value $<0.01$. This indicates that their performances are not same due to the different values of the mentioned health and nutrition related variables. The study found negative association between socio-economic parameters and school performance. As the p-value is zero the relationship between the school performances with socioeconomic parameters is highly significant.

Table 4. Cross tabulation of Individual Dietary Diversity Score (IDDS) of respondent and marks achieved in class 4 final exam

\begin{tabular}{llccccc}
\hline \multicolumn{7}{c}{ Marks Achieved In Class 4 Final Exam } \\
\hline \multicolumn{1}{c}{ IDDS } & & $<500$ & $500-599$ & $600-699$ & 700 and above & Total \\
\hline $\begin{array}{l}\text { Consumption of dark green } \\
\text { vegetables }\end{array}$ & & $1(3.2)$ & $1(3.2)$ & $14(45.2)$ & $15(48.4)$ & $31(38.8)$ \\
Consumption of fruits & & $5(15.2)$ & $3(9.1)$ & $9(27.3)$ & $16(48.5)$ & $33(41.2)$ \\
Consumption of eggs & $3(12.5)$ & $1(4.2)$ & $4(16.7)$ & $16(66.7)$ & $24(30)$ \\
Consumption of flesh meats & $7(20.6)$ & $8(23.5)$ & $3(8.8)$ & $16(47.1)$ & $34(42.5)$ \\
Consumption of fish and sea foods & $7(19.4)$ & $5(13.9)$ & $10(27.8)$ & $14(38.9)$ & $36(45)$ \\
Consumption of milk and milk product & $1(3.3)$ & $3(10)$ & $7(23.3)$ & $19(63.3)$ & $30(37.5)$ \\
\hline
\end{tabular}


Table 4 shows that the school performance measured by marks of the student is related with Individual Dietary Diversity Score (IDDS). 45 percent students consumed fish and sea foods. Among them 38.9 percent obtained highest marks. 42.5 percent students consumed flesh meats and 47.1 percent of them achieved highest marks. Consumption of fruits was 41.2 percent of which 48.5 percent students obtained highest marks. 38.8 percent students consumed dark green leafy vegetables of which 48.4 percent achieved highest marks. It is alarming that majority of the students (62.5 percent) did not consume milk and milk product; only 37.5 percent students consumed milk and milk products. Majority of the students (63.3 percent) of highest marks group consumed milk and milk product. Consumption of eggs among highest mark group is high. 30 percent students consumed eggs of which 66.7 percent got highest marks in class 4 final exam.

\section{DISCUSSION}

In this study school performance was measured by class roll number. The lower the class roll number, the better the school performance. School performance of the students was severely affected by mothers' nutritional knowledge. A lot of nutritional knowledge factors are available. Family background is the key to a students' life and outside of school, is the most important influence on student learning [10]. There are numerous health and nutritional factors which affects the school performance. Dietary diversity scores are created by summing either the number of individual foods or food groups consumed over a reference period. The dietary diversity scores consist of a simple count of food groups that a household or an individual has consumed over the past 24 hours. Studies undertaken in pre-industrial societies show that children with a few years of formal schooling perform better than their unschooled peers on a variety of cognitive tests [11].

Students who have a low Socio Economic Status earn lower test scores and are more likely to drop out of school [11]. Class performance was negatively correlated with the factors total income of the family, monthly tuition cost, number of earning persons in the family, and this correlation was significant $(p<0.01)$ at 1 percent level of significance. Research shows that supportive and attentive parenting practices positively affect academic achievement. Maternal characteristics are another key factor that affects academic achievement [12].

\section{CONCLUSION}

In conclusion, it may be said that school performance of the selected students varies due to mothers' nutritional knowledge, health and nutritional factors and socio-economic parameters. School performance measured by marks group of the students was significantly related with those. A lot of nutritional knowledge factors are available. Among those we gave emphasis on the effects of mothers knowledge score, BMI, socio-economic factor on School performance. Although this study provides a general idea, more remains to be learned about the role of child health, and on what policies (either in the school or in the Family) are most effective at addressing children's school performance and health problems. Finally it can be said maternal nutritional knowledge play a crucial role on the nutritional status of children. It is therefore important that mothers are educated on proper nutrition so that they could cater to the growing needs and for a better nutritional status of their children.

\section{REFERENCES}

[1] Anurag S., Syed EM., Payal MS., Ved PS., Bhushan K., “Nutritional status of school-age children - Ascenario of urban slums in India”, Archives of Public Health, vol/issue: 70(8), 2012. Available: http://www.archpublichealth.com/content/70/1/8.

[2] WHO, "Primary School Physical Environment and Health”,WHO Global School Health Initiative. WHO Information series on school health, Document Two. WHO, SIDA, 1997.

[3] Desforges C.,Abouchaar A., “The Impact of Parental Involvement, Parental Support and Family Education on Pupil Achievements and Adjustment”,A Literature Review, RR433, pp. 12, 2003.

[4] Aziz M.,Khattak AM.,Shehla G., Sidra TM., Jamal U., "Evaluation of nutritional knowledge of mothers about their children”,Gomal Journal of Medical Sciences, vol/issue: 5(1), pp.17, 2007.

[5] Ruel MT.,Habicht JP.,Pinstrup-Andersen P.,Grohn Y., “The Mediating Effect of Maternal Nutrition Knowledge on the Association between Maternal Schooling and Child Nutritional Status in Lesotho",American Journal of Epidemiology, vol/issue: 135(8), pp.904-14, 1992.

[6] Alderman H., Behrman JR.,Lavy V.,Menon R., "Child Health and School Enrollment: A Longitudinal Analysis",Journal of Human Resources, vol.36, pp.185-205, 2001.

[7] Lockheed ME.,Adriaan M.,Verspoor, "Improving Primary Education in Developing Countries: A Review of Policy Options”,Washington, D.C.: The World Bank, 1990. 
[8] Dagalea DAA., "The effect of a nutrition education module on the knowledge, attitude and practices of mothers with undernourished children aged $0-5$ years old on nutrition in Barangay Biayon, Sergio Osmeña SR.; Zamboanga Del Norte”, The Faculty of Ateneo de Zamboanga University School of Medicine, 2005.

[9] Jeynes WH., "Examining the effects of parental absence on the academic achievement of adolescents: the challenge of controlling for family income",Journal of Family and Economic Issues,vol/issue: 23(2), 2002.

[10] Majoribanks K., “Family Learning Environmentsans Students' Outcomes: Review”,Journal of Comparative Family Studies, vol/issue:27(2), pp.373-394, 1996.

[11] Pollitt E., "Malnutrition and Infection in the Classroom”,Paris: UNESCO, 1990.

[12] Farooq MS., Chaudhry AH., Shafiq M., Berhanu G., "Factors affecting students' quality of academic performance: a case of secondary school level”, Journal of Quality and Technology Management, vol/issue: 7(2), pp.1-14, 2011. 